\title{
Blue Covarine Toothpaste versus Office Whitening: Which is the Most Effective on Stained Teeth?
}

\section{Creme Dental de Blue Covarine Versus Clareamento de Consultório: Qual é o Mais Efetivo em Dentes Pigmentados?}

\author{
anniversidade de São Paulo, Department of Restorative Dentistry. SP, Brazil \\ ${ }^{\mathrm{b}}$ University of Toronto, Faculty of Dentistry. Canada. \\ *E-mail: aryveltomirand@gmail.com
}

Andrea Abi Rached Dantasa; Vinicius Perassoli Menegazzo; ${ }^{a}$;ryvelto Miranda Silva ${ }^{a}$; João Felipe Besegato Janaina Freitas Bortolatto ${ }^{\mathrm{b}}$; Michael Christopher Floros ${ }^{\mathrm{b}}$; Suzana Santos Araujo ; Osmir Batista de Oliveira Júnior ${ }^{\mathrm{a}}$

\begin{abstract}
Alternative whitening strategies to hydrogen peroxide have been proposed, such as the inclusion of abrasive and/or pigmented particles in the toothpaste. This study compared the whitening effectiveness of a toothpaste containing Blue Covarine (BC) vs. an in-office whitening treatment using $35 \%$ hydrogen peroxide (HP) in teeth stained. Bovine incisors blocks $(6.0 \times 6.0 \times 2.0 \mathrm{~mm})$ were stained with green tea (GT), orange soda $(\mathrm{OS})$, or red wine (RW). The samples were randomly assigned into 8 groups $(\mathrm{n}=15)$, according to the type of staining and whitening treatment: G1 - no staining, BC (Control); G2 - no staining, HP (Control); G3 - GT, BC; G4 - GT, HP; G5 - OS, BC; G6 - OS, HP; G7 - RW, BC; G8 $\mathrm{RW}$, HP. Color change $(\Delta \mathrm{E})$, luminosity $\left(\mathrm{L}^{*}\right)$, green-red axis $\left(\mathrm{a}^{*}\right)$, and blue-yellow axis $\left(\mathrm{b}^{*}\right)$ were recorded with spectroscopy at T0 - baseline, T1 - immediately after toothbrushing or in-office tooth whitening, and T2 - after the conclusion of the treatments. The whiteness index for dentistry (WID) was calculated. Data were analyzed by two-way repeated measured mixed ANOVA and Bonferroni test $(\alpha=0.05)$. HP showed a better whitening performance $(\Delta \mathrm{E})(\mathrm{p} \leq 0.042)$. Otherwise, no effects of the whitening agent were observed $(\mathrm{p}=1.000)$. Data from $\Delta \mathrm{L}, \Delta \mathrm{a}$, and $\Delta \mathrm{b}$ showed statistically significant differences for experimental groups $(\mathrm{p}<0.001)$. In the WID analysis, BC and HP had similar effects within control and RW groups. In conclusion, blue covarine toothpaste may be a viable option for extrinsically stained teeth. However, for severe staining, HP-based whitening agents proved to be the most effective treatment strategy.
\end{abstract}

Keywords: Tooth Bleaching. Dentifrices. Color.

\section{Resumo}

Estratégias de clareamento alternativas ao peróxido de hidrogênio têm sido propostas, como a inclusão de partículas abrasivas elou pigmentadas nos cremes dentais. Este estudo comparou a eficácia clareadora de um creme dental contendo Blue Covarine (BC) com um tratamento de clareamento em consultório com peróxido de hidrogênio a 35\% (HP) em dentes pigmentados. Blocos de incisivos bovinos $(6,0 \times 6,0 \times 2,0 \mathrm{~mm})$ foram pigmentados com chá verde (GT), refrigerante de laranja (OS) ou vinho tinto (RW). As amostras foram distribuídas aleatoriamente em 8 grupos $(n=15)$, de acordo com o tipo de pigmento e tratamento clareador: G1 - sem coloração, CB (Controle); G2 - sem coloração, HP (Controle); G3 - GT, BC; G4 - GT, HP; G5 - OS, BC; G6 - SO, HP; G7 - RW, BC; G8 - RW, HP. Mudança de cor $(\Delta E)$, luminosidade $\left(L^{*}\right)$, eixo verde-vermelho $\left(a^{*}\right)$ e eixo azul-amarelo $\left(b^{*}\right)$ foram registrados com espectroscopia em T0 - baseline, T1 imediatamente após a escovação ou clareamento dental em consultório, e T2 - após a conclusão dos tratamentos. O índice de brancura para odontologia (WID) foi calculado. Os dados foram analisados por ANOVA mista de duas vidas para medidas repetidas e teste de Bonferroni ( $\alpha$ $=0,05)$. HP apresentou melhor desempenho de clareamento $(\Delta E)(p \leq 0,042)$. Os dados de $\Delta L, \Delta a$ e $\Delta b$ mostraram diferenças estatisticamente significativas para os grupos experimentais ( $<0,001)$. Na análise WID, BC e HP tiveram efeitos semelhantes nos grupos controle e RW. Em conclusão, o creme dental covarine azul pode ser uma opção viável para dentes com coloração extrínseca. No entanto, para manchas graves, os agentes de clareamento à base de HP provaram ser a estratégia de tratamento mais eficaz.

Palavras-chave: Clareamento Dental. Dentifrícios. Cor.

\section{Introduction}

Stained teeth present organic compounds, such as conjugated chains of single or double bonds, that are responsible to produce the stains. When these conjugated chains and other functional groups are broken by oxidant agents, a whitening effect is achieved. ${ }^{1}$ Therefore, conventional tooth whitening techniques mainly use peroxides as oxidant agents to be diffused into the tooth organic matrix and release free radicals ${ }^{2}$ that interact with the organic compounds and generate lighter compounds. ${ }^{3,4}$

Despite the well-known effectiveness of peroxides against stained teeth, they might negatively influence the teeth biological components ${ }^{5,6}$ and frequently display clinical side effects resulting in trans and postoperative hypersensitivity. ${ }^{7,8}$ Dental professional supervision is always required when peroxide-based whitening procedures are performed. To simplify the technique and make the whitening effect easier to obtain for patients, whitening toothpastes have been developed. However, the properly delivery of toothpaste peroxides is challenging regarding formulation factors, regulatory restrictions, and relatively short exposure time during toothbrushing. ${ }^{9}$ To overcome all these limitations, 
peroxide-free formulations of whitening toothpastes have recently emerged as an easier and safer alternative. While peroxides whiten teeth by chemically modifying pigments on and within the tooth structure itself, peroxide-free whitening toothpastes work by removing and/or controlling extrinsic stain with optimized abrasives, surfactants, polyphosphates, and enzymes. ${ }^{7}$

Whitening toothpastes can be classified according to their mechanism of action: chemical, abrasive, or optical effect. ${ }^{7}$ Blue Covarine $[\mathrm{BC}]$ is a whitening agent that works by the optical effect mechanism. Its activity is based on the deposition of a thin film of blue pigment on the enamel surface, which modifies the tooth perceived color. ${ }^{10}$ This "whitening effect" was based on the work of a number of previous studies ${ }^{11,12}$ which demonstrated that the whitening perception, both visual and instrumental [spectrophotometers and colorimeters], depends more on changes in the $\mathrm{b}^{*}$ [blue-yellow] coordinate than the luminosity [L*] from the CIELab system. ${ }^{13,14}$ Despite the promising findings regarding $\mathrm{BC}$, further investigations are still required..$^{15}$ To obtain an optical whitening, the $\mathrm{BC}$ blue shade must predominate over the yellow color of stained teeth. ${ }^{16}$

Consumption of products with dyes in a variety of colors such as red wine, green tea, acai berry, orange juice, black tea, coffee, cola soft drinks and cigarettes may result in stained teeth. ${ }^{17}$ Therefore, it is crucial to compare the whitening efficacy of a BC-based whitening toothpastes in teeth stained by different types of pigments. Moreover, comparison with conventional peroxide-based whitening agents will provide valuable information regarding the potential strengths and limitations of each whitening treatment.

This randomized blinded in vitro study aimed to compare the whitening effect of a new toothpaste containing BC with a conventional in-office tooth whitening treatment. The null hypothesis tested was that toothpaste containing $\mathrm{BC}$ exhibits similar whitening effect on stained teeth to a conventional in-office whitening treatment using $35 \%$ hydrogen peroxide (HP).

\section{Material and Methods}

\subsection{Study design}

A controlled laboratory, randomized, paired and singleblinded (color examiner) study was performed. The dependent variable was the whitening effectiveness, evaluated according to the changes in total color $(\Delta \mathrm{E})$, luminosity $\left(\mathrm{L}^{*}\right)$, greenred $\left(a^{*}\right)$ and blue-yellow $\left(b^{*}\right)$ axis, and whitening index for dentistry $\left(\mathrm{WI}_{\mathrm{D}}\right)$. The independent variables were: a) Whitening treatment - two levels: in-office tooth whitening using 35\% $\mathrm{HP}$ and toothpaste containing $\mathrm{BC}$; b) Tooth structure staining - three different colored types of pigments: green tea - GT, red wine - RW and orange soda - OS) and c) Evaluation time - three levels: baseline, immediately after the first tooth whitening treatment, and at the end of the treatment.
The evaluation time was also used to generate the repeated measures variable.

\subsection{Sample size calculation}

The sample size for repeated measures ( $n=15$ /group) was defined using the $\mathrm{G}^{*}$ Power 3.1.9 software $^{18}$ considering a minimum effect size of $20 \%-(\Delta \mathrm{E})$ as the primary outcome ${ }^{19}$ $80 \%$ statistical power and 5\% significance level.

\subsection{Samples preparation}

Bovine incisors were obtained from an officially regulated abattoir. After prophylaxis, 120 bovine incisors were selected according to good structural integrity and surface regularity. First, the teeth roots were removed using a water-cooled precision cutter machine (IsoMet 4000, Buehler Ltd., Lake Bluff, IL). Then, the teeth were sectioned in mesiodistal directions and cervical-incisal to obtain dental blocks of 6.0 x 6.0 x $2.0 \mathrm{~mm}$. The obtained blocks had their vestibular and palatine surfaces corrected in a polishing machine (Ecomet 250/Automet 250 - Buehler Ltd., Lake Bluff, IL, USA) to obtain flat surfaces. The blocks had a total thickness of 2 $\mathrm{mm}$ consisting of $1 \mathrm{~mm}$ of enamel and $1 \mathrm{~mm}$ of dentin, with dimensions measured using a digital caliper (Model 500-144B, Mitutoyo Sul América Ltda. SP, Brazil). The samples were numbered and randomly assigned using BioEstat version 5.3 for Windows (Instituto Mamirauá, Tefé, AM, Brazil) (Figure 1). The grouped samples were then embedded in a neutral gray colored acrylic resin in sets of five dental blocks (38.0 x 10.0 x $2.0 \mathrm{~mm}$ each set). Each block was coded and stored in artificial saliva under stirring at controlled temperature $\left(36 \pm 1.0^{\circ} \mathrm{C}\right)$ for one week prior to testing. The 24 experimental sets were randomly distributed in 8 experimental groups $(n=15)$, according to the type of whitening treatment and type of pigmentation, as described in Figure 1.

Figure 1 - Flow-chart of the study

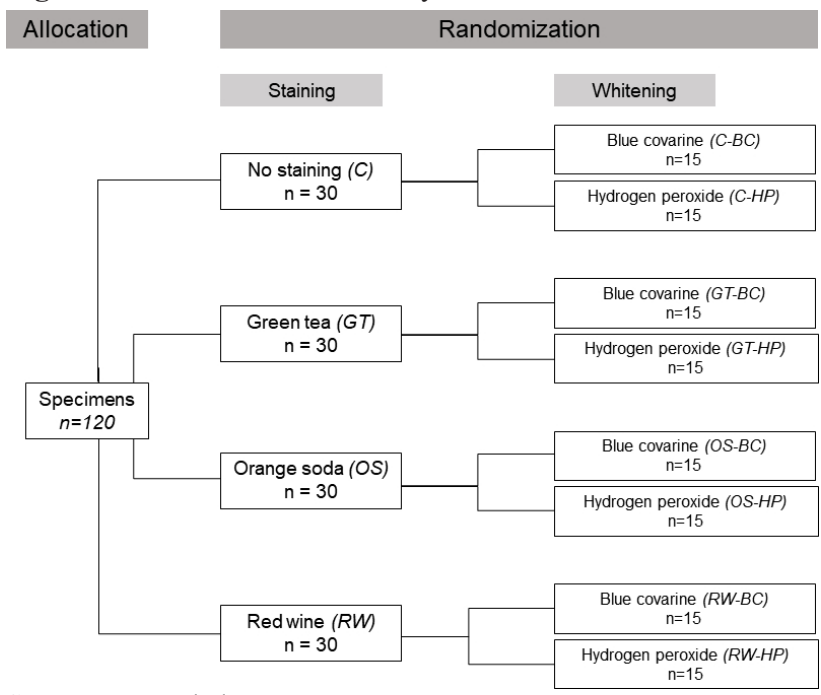

Source: Research data. 


\subsection{Staining Procedures}

The previous dental blocks staining was carried out according to the methodology proposed by Stookey et al. ${ }^{19}$ and modified to only provide the dental structure staining without the formation of a bacterial biofilm. Prior to staining, the exposed dentin surface was waterproofed by 2 layers of clear nail polish (Colorama, Brazil). After drying for 1 hour, the enamel surface was conditioned by immersion in a $1 \%$ hydrochloric acid $(0.12 \mathrm{~N})$ for 60 seconds. Immediately after that, the samples were transferred to a saturated solution of sodium carbonate for 30 seconds to neutralize the remaining acid. The samples were finally washed in deionized water for 1 minute (19). Sample sets were then subjected to periods of staining by total immersion in a pigment solution and drying periods in equipment like that used by Stookey et al. ${ }^{19}$ for 4 consecutive days, at a controlled temperature of $36 \pm 1{ }^{\circ} \mathrm{C}$. The staining solutions tested were green tea $-\mathrm{GT}$, orange soda - OS and red wine - RW. The control groups were not subjected to any dye solution and remained in artificial saliva.

\subsection{Whitening Protocols}

$\mathrm{BC}$ groups underwent toothbrushing in a brushing test machine (MAVTEC - Comércio e Serviços e Desenvolvimento para Laboratório, Ribeirão Preto, SP, Brazil). The experimental sets were fixed in the machine and brushed with a toothpaste containing Blue Covarine (BC) in 3-minute daily cycles to simulate the standard brushing protocol recommended for patients (1 minute of brushing 3 times per day). The procedure was repeated for 7 consecutive days. Toothpastes were dissolved in distilled water and a $0.5 \%$ sodium carboxymethyl cellulose solution (CMCS), in the toothpaste:water:CMCS ratio of $1: 1: 1$, following a procedure published by Joiner et al. ${ }^{7.9}$ The brushing test machine was programmed to brush at $150 \mathrm{cycles} / \mathrm{min}$, with a load of $375 \mathrm{~g}$, resulting in a total of 450 brushing cycles per day. After brushing, each study group was washed with water to remove any remaining toothpaste and was stored in artificial saliva. The HP groups were subjected to in-office tooth whitening using 35\% HP (Whiteness HP, FGM Produtos Odontológicos, Joinville, SC, Brazil). The whitening agent was prepared as recommended by the manufacturer's instructions. Two whitening sessions were performed with an interval of 7 days between them. In each whitening sessions, the whitening agent was applied for three times for 15 minutes. After each session, the sample sets were washed with water and placed in artificial saliva. The total cumulative contact time of the whitening agent with the dental enamel was 90 minutes.

\subsection{Whitening Effectiveness}

The effectiveness was measured by a previously calibrated $(\mathrm{CCI}=0.74)$ and blinded examiner, using a Vita
EasyShade ${ }^{\circledast}$ reflectance spectrophotometer (Vita, CA, USA) with black background. The analyses were determined based on $\Delta \mathrm{L}, \Delta \mathrm{a}$ and $\Delta \mathrm{b}$, from the CIELab color system and assessed at $\mathrm{T} 1$ - immediately after the first toothbrushing or first in-office tooth whitening treatment, T2 - after conclusion of all of the whitening treatments. The difference was considered between baseline color compared to the subsequent evaluations time ( $\mathrm{T} 1$ and $\mathrm{T} 2$ ). $\Delta \mathrm{E}$ was further calculated using the following formula: [20] $\Delta \mathrm{E}=\left[\left(\mathrm{L}_{\mathrm{i}}-\mathrm{L}_{\mathrm{o}}\right)^{2}\right.$ $\left.\left.+\left(a_{i}-a_{o}\right)^{2}+\left(b_{i}-b_{o}\right)^{2}\right)^{1 / 2}\right]$.

\subsubsection{Whitening Index for Dentistry}

The whitening index for dentistry $\left(\mathrm{WI}_{\mathrm{D}}\right)$ was calculated according to the equation: WID $=0.511 \mathrm{~L}^{*}-2.324 \mathrm{a}^{*}$ $1.100 b^{*}{ }^{21}$

\subsection{Data analysis}

Data for color differences $(\Delta \mathrm{E})$ and each CIELab color axis $\left(L^{*}, a^{*}\right.$ and $\left.b^{*}\right)$ were analyzed by a two-way repeated measure mixed ANOVA. Primarily, the conditions for the application of this test, namely normal distribution and sphericity were tested through the Shapiro-Wilk ( $\mathrm{p} \geq 0.056$ ) and Mauchly ( $<<$ $0.001)$ tests, respectively. The Mauchly test indicated the need for using the Greenhouse-Geisser correction. The Bonferroni test was used for the pairwise comparisons of interest. All the statistical tests were performed with the assistance of PAWS Statistics Software (PASW Statistics 22.0, SPSS Inc, Chicago, IL, USA) considering a significance level of $5 \%$.

\section{Results and Discussion}

Two-way repeated measured mixed ANOVA showed statistically significant differences for the experimental groups $(p<0.001)$ and for the interaction of groups and evaluations time ( $p=0.022)$. No difference for the evaluations time was observed ( $\mathrm{p}=0.126$ ). According to the color change $(\triangle \mathrm{E}) \mathrm{BC}$ toothpaste promoted a whitening of the structure. However, this whitening effect was not like HP $(p \leq 0.042)$. To the groups that received pigmented solutions, HP always showed a better whitening performance. Otherwise, for control groups (without pigmented solutions) no effects of the whitening agent were observed $(p=1.000)$. The most color changes were observed in GT and RW for HP, both to $\mathrm{T} 1$ and T2. Regarding the evaluations time, only for CT and GT groups, a second session provided a whitening effect $(\mathrm{p} \leq 0.030)$, regardless of the whitening products used (Table $1)$. 
Table 1 - Means and standard deviation for color change $(\Delta \mathrm{E})$ for all the experimental groups at different time points

\begin{tabular}{|c|c|c|c|c|c|c|c|c|}
\hline \multirow{2}{*}{ Time points } & \multicolumn{7}{|c|}{ Experimental Groups } \\
\cline { 2 - 9 } & BC-C & HP-C & BC-GT & HP-GT & BC-OS & HP-OS & BC-RW & HP-RW \\
\hline T1 & $13.4 \pm 3.9^{\mathrm{Bb}}$ & $12.9 \pm 3.9^{\mathrm{Bb}}$ & $4.3 \pm 1.6^{\mathrm{Aa}}$ & $19.5 \pm 7.9^{\mathrm{BCa}}$ & $4.4 \pm 2.6^{\mathrm{Aa}}$ & $10.3 \pm 3.4^{\mathrm{Ba}}$ & $13.9 \pm 4.3^{\mathrm{ABa}}$ & $26.9 \pm 6.4^{\mathrm{Ca}}$ \\
\hline $\mathrm{T} 2$ & $11.3 \pm 3.8^{\mathrm{ABCa}}$ & $10.6 \pm 4.8^{\mathrm{ABCa}}$ & $8.2 \pm 4.2^{\mathrm{ABb}}$ & $21.9 \pm 10.7^{\mathrm{CDb}}$ & $4.9 \pm 1.3^{\mathrm{Aa}}$ & $11.1 \pm 3.7^{\mathrm{BCa}}$ & $14.0 \pm 6.3^{\mathrm{ABCa}}$ & $29.1 \pm 6.9^{\mathrm{Da}}$ \\
\hline
\end{tabular}

Different uppercase letters indicate significant differences at each time point $(\mathrm{p} \leq 0.042)$. Different lowercase letters indicate statistically significant differences among the different time points in the same group $(\mathrm{p} \leq 0.030)$. T1: immediately after the first toothbrushing or first in-office tooth whitening treatment; T2: after conclusion of all of the whitening treatments; BC: Blue covarine toothpaste; HP: hydrogen peroxide 35\%; C: Control; GT: Green tea; OS: Orange soda; RW: Red wine.

Source: Research data.

In terms of luminosity of the enamel structure $(\Delta \mathrm{L})$ statistically significant differences for the experimental groups $(p<0.001)$, for evaluations time $(p=0.035)$ and for the interaction of these factors $(\mathrm{p}=0.022)$ were observed. HP showed a better performance for GT and
RW groups $(\mathrm{p}=0.007$ and $\mathrm{p}<0.001$, respectively). For OS, no statistically significant difference was observed $(\mathrm{p}=1.000)$, except for $\mathrm{T} 2(\mathrm{p}=0.015)$. For the control groups, BC exhibited higher luminosity change than HP $(\mathrm{p} \leq 0.034)$ (Table 2).

Table 2 - Means and standard deviation for luminosity $(\Delta \mathrm{L})$ for all the experimental groups at different time points

\begin{tabular}{|c|c|c|c|c|c|c|c|c|}
\hline \multirow{2}{*}{ Time points } & \multicolumn{7}{|c|}{ Experimental groups } \\
\cline { 2 - 8 } & BC-C & HP-C & BC-GT & HP-GT & BC-OS & HP-OS & BC-RW & HP-RW \\
\hline T1 & $16.4 \pm 3.8^{\mathrm{Cb}}$ & $24.9 \pm 5.7^{\mathrm{Bb}}$ & $6.3 \pm 3.7^{\mathrm{Aa}}$ & $30.7 \pm 9.6^{\mathrm{Ca}}$ & $16.1 \pm 8.7^{\mathrm{ABa}}$ & $31.3 \pm 11.7^{\mathrm{Ba}}$ & $78.4 \pm 8.6^{\mathrm{BCa}}$ & $82.4 \pm 10.8^{\mathrm{Da}}$ \\
\hline $\mathrm{T} 2$ & $10.3 \pm 3.6^{\mathrm{CDa}}$ & $18.5 \pm 4.8^{\mathrm{Aa}}$ & $16.8 \pm 3.6^{\mathrm{ACb}}$ & $56.3 \pm 14.6^{\mathrm{BDEb}}$ & $17.4 \pm 4.8^{\mathrm{ACa}}$ & $56.6 \pm 12.9^{\mathrm{BDb}}$ & $52.7 \pm 9.7^{\mathrm{ACDa}}$ & $81.6 \pm 9.6^{\mathrm{Ea}}$ \\
\hline
\end{tabular}
Different uppercase letters indicate significant differences at each time point ( $\leq \leq 0.042)$. Different lowercase letters indicate statistically significant differences among the different time points in the same group $(\mathrm{p}<0.001)$.T1: immediately after the first toothbrushing or first in-office tooth whitening treatment; T2: after conclusion of all of the whitening treatments; BC: Blue covarine toothpaste; HP: hydrogen peroxide 35\%; C: Control; GT: Green tea; OS: Orange soda; RW: Red wine.

Source: Research data.

The data of green-red axis $(\Delta \mathrm{a})$ showed statistically significant difference for the experimental groups $(\mathrm{p}<$ $0.001)$, for evaluations time $(\mathrm{p}=0.007)$ and for the interaction of these factors $(\mathrm{p}<0.001)$. Moreover, the data showed that a second session provided a variation in this axis only to the control groups $(\mathrm{p}=0.003)$. In $\mathrm{T} 1$, the type of whitening products had an effect only for GT groups $(\mathrm{p}<0.001)$ (Table 3).

Table 3 - Means and standard deviation for $\Delta$ a for all the experimental groups at different time points

\begin{tabular}{|c|c|c|c|c|c|c|c|c|}
\hline \multirow{2}{*}{ Time points } & \multicolumn{7}{|c|}{ Experimental groups } \\
\cline { 2 - 8 } & BC-C & HP-C & BC-GT & HP-GT & BC-OS & HP-OS & BC-RW & HP-RW \\
\hline T1 & $3.1 \pm 1.1^{\mathrm{ABa}}$ & $2.0 \pm 1.4^{\mathrm{ABa}}$ & $1.1 \pm 0.5^{\mathrm{Aa}}$ & $12.3 \pm 4.8^{\mathrm{Da}}$ & $1.6 \pm 0.7^{\mathrm{Aa}}$ & $2.5 \pm 0.9^{\mathrm{ABa}}$ & $6.4 \pm 2.7^{\mathrm{BCDa}}$ & $7.5 \pm 3.9^{\mathrm{ACDa}}$ \\
\hline $\mathrm{T} 2$ & $3.1 \pm 4.6^{\mathrm{CDa}}$ & $3.8 \pm 2.2^{\mathrm{BCb}}$ & $0.7 \pm 0.4^{\mathrm{Aa}}$ & $10.2 \pm 4.3^{\mathrm{BCDa}}$ & $2.2 \pm 0.9^{\mathrm{ABa}}$ & $5.4 \pm 1.3^{\mathrm{ACDa}}$ & $6.4^{\mathrm{A}} \pm 2.2^{\mathrm{BCa}}$ & $7.5 \pm 3.5^{\mathrm{ACDa}}$ \\
\hline
\end{tabular}
Different uppercase letters indicate significant differences at each time point $(\mathrm{p} \leq 0.040)$. Different lowercase letters indicate statistically significant differences among the different time points in the same group $(\mathrm{p} \leq 0.002)$. T1: immediately after the first toothbrushing or first in-office tooth whitening treatment; T2: after conclusion of all of the whitening treatments; BC: Blue covarine toothpaste; HP: hydrogen peroxide 35\%; C: Control; GT: Green tea; OS: Orange soda; RW: Red wine.

Source: Research data.

Data from the blue-yellow axis $(\Delta \mathrm{b})$ showed statistically significant difference for the experimental groups $(\mathrm{p}<0.001)$, for evaluations time $(\mathrm{p}=0.005)$ and for the interaction of these factors $(p=0.018)$. The type of

whitening products showed no effect for GT and CT groups ( $\mathrm{p}=0.105$ and $\mathrm{p}=0.124$, respectively). In $\mathrm{T} 2$, the type of whitening products had an effect only in OS $(p=1.000)$ (Table 4).

Table 4 - Means and standard deviation for $\Delta \mathrm{b}$ for all the experimental groups at different time points

\begin{tabular}{|c|c|c|c|c|c|c|c|c|}
\hline \multirow{2}{*}{$\begin{array}{c}\text { Time } \\
\text { points }\end{array}$} & \multicolumn{7}{|c|}{ Experimental groups } \\
\cline { 2 - 9 } & BC-C & HP-C & BC-GT & HP-GT & BC-OS & HP-OS & BC-RW & HP-RW \\
\hline $\mathrm{T} 1$ & $19.6 \pm 4.6^{\mathrm{BCb}}$ & $47.6 \pm 6.8^{\mathrm{CEb}}$ & $12.6 \pm 6.7^{\mathrm{ABa}}$ & $36.4 \pm 7.1^{\mathrm{ACDEb}}$ & $7.2 \pm 3.3^{\mathrm{Aa}}$ & $38.1 \pm 7.9^{\mathrm{BCDEb}}$ & $23.3 \pm 6.3^{\mathrm{ACDa}}$ & $77.2 \pm 14.9^{\mathrm{Ea}}$ \\
\hline $\mathrm{T} 2$ & $7.9 \pm 2.6^{\mathrm{ABa}}$ & $33.2 \pm 8.3^{\mathrm{Da}}$ & $20.1 \pm 7.4^{\mathrm{BCb}}$ & $17.7 \pm 3.4^{\mathrm{ABCa}}$ & $3.9 \pm 2.4^{\mathrm{Aa}}$ & $28.7 \pm 9.5^{\mathrm{CDEa}}$ & $26.2 \pm 5.8^{\mathrm{BCDEa}}$ & $86.3 \pm 18.4^{\mathrm{Ea}}$ \\
\hline
\end{tabular}

Different uppercase letters indicate significant differences at each time point ( $\mathrm{p} \leq 0.013)$. Different lowercase letters indicate statistically significant differences among the different time points in the same group $(\mathrm{p} \leq 0.030)$.T1: immediately after the first toothbrushing or first in-office tooth whitening treatment; T2: after conclusion of all of the whitening treatments; BC: Blue covarine toothpaste; HP: hydrogen peroxide 35\%; C: Control; GT: Green tea; OS: Orange soda; RW: Red wine.

Source: Research data. 
In the $\mathrm{WI}_{\mathrm{D}}$ analysis (Table 5), a statistically significant difference for the experimental groups $(p<0.001)$ and for the interaction experimental group*evaluation time $(\mathrm{p}=0.021)$ were observed, but not for evaluation time $(\mathrm{p}=0.089)$. The conclusion of all the whitening treatments (T2) showed the difference to $\mathrm{T} 1$ in the $\mathrm{C}(\mathrm{p}=0.039)$ and $\mathrm{OS}(0.047)$ groups which received hydrogen peroxide whitening treatment, and in the $\mathrm{C}$ group blue-covarine whitened $(\mathrm{p}=0.002)$. Regardless of the evaluation time, the whitening agents had similar effects in the control groups and those stained with RW.

Table 5 - Means and standard deviation for whitening index for dentistry $\left(\mathrm{WI}_{\mathrm{D}}\right)$ for all the experimental groups at different time points

\begin{tabular}{|c|c|c|c|c|c|c|c|c|}
\hline \multirow{2}{*}{$\begin{array}{c}\text { Time } \\
\text { points }\end{array}$} & \multicolumn{7}{|c|}{ Experimental groups } \\
\cline { 2 - 9 } & BC-C & HP-C & BC-GT & HP-GT & BC-OS & HP-OS & BC-RW & HP-RW \\
\hline $\mathrm{T} 1$ & $-5.8 \pm 4.8^{\mathrm{Ab}}$ & $-0.8 \pm 4.8^{\mathrm{ABCb}}$ & $-4.9 \pm 3.3^{\mathrm{Aa}}$ & $17.5 \pm 8.7^{\mathrm{BCa}}$ & $-2.3 \pm 1.1^{\mathrm{ABa}}$ & $16.3 \pm 7.9^{\mathrm{Cb}}$ & $-5.2 \pm 3.8^{\mathrm{Aa}}$ & $-1.7 \pm 0.8^{\mathrm{ABa}}$ \\
\hline $\mathrm{T} 2$ & $-10.9 \pm 6.6^{\mathrm{Aa}}$ & $-1.9 \pm 7.3^{\mathrm{ABCD}}$ & $-3.6 \pm 1.6^{\mathrm{Ba}}$ & $17.1 \pm 8.2^{\mathrm{CDa}}$ & $-0.3 \pm 0.7^{\mathrm{BCa}}$ & $14.6 \pm 8.7^{\mathrm{Da}}$ & $-7.6 \pm 3.4^{\mathrm{ABa}}$ & $-2.6 \pm 1.9^{\mathrm{ABCa}}$ \\
\hline
\end{tabular}

Different uppercase letters indicate significant differences at each time point $(\mathrm{p} \leq 0.037)$. Different lowercase letters indicate statistically significant differences among the different time points in the same group $(\mathrm{p} \leq 0.047)$. T1: immediately after the first toothbrushing or first in-office tooth whitening treatment; T2: after conclusion of all of the whitening treatment; BC: Blue covarine toothpaste; HP: hydrogen peroxide 35\%; C: Control; GT: Green tea; OS: Orange soda; RW: Red wine.

Source: Research data.

The use of whitening toothpaste with an optical effect agent has been proposed as an alternative treatment for mild tooth structure discolorations. ${ }^{10}$ This study evaluated the potential of a BC toothpaste compared to conventional HP-based inoffice whitening agent in stained teeth. It was observed that $\mathrm{BC}$ toothpaste promotes a significant color change, but not comparable with HP. This result leads us to reject the null hypothesis tested.

The "optical" whitening effect of $\mathrm{BC}$ toothpaste is based on the perception alteration of the original tooth color due to the deposition of a thin bluish-colored film on the tooth structure after brushing, altering the tooth color perception. This toothpaste has also an effective abrasive system for the removal of extrinsic stains in comparison to other silica whitening toothpaste. ${ }^{15}$ The main advantage is a significant and instantaneous whitening of the dental structure without requiring HP-based products that cause biological damage to the dental structure. ${ }^{6,8,22}$

To the best level of knowledge, this is the first study that carried out a direct comparison of the whitening potential of $\mathrm{BC}$ toothpaste versus a HP-based whitening agent in stained teeth. Our results have shown that the HP whitening effect was significantly higher than BC for stained teeth, regardless of the dyes used. However, Bergesch et al..$^{23}$ and Oliveira et al..$^{24}$ evaluated the effect of $\mathrm{BC}$ in comparison to other dentifrices on stained teeth. It was observed that even in the analysis immediately after toothbrushing, BC showed whitening potential, mainly by increasing the teeth brightness. This result can be justified by a possible weak adhesion of the pigments to the teeth surface, as they have been subjected to extrinsic pigmentation. Thus, the abrasive system composed by hydrated silica particles may have been effective for removing stains.

The color perception is given by a three-dimensional space defined by the International Commission of l'Eclairage [CIE] in $1986 .{ }^{25}$ The three axes are $\mathrm{L}^{*}, \mathrm{a}^{*}$ and $\mathrm{b}^{*}$, where $\mathrm{L}$ *represents a measure of luminosity and the axes $\mathrm{a}^{*}$ and $\mathrm{b}^{*}$ represent the red-green and blue-yellow axes, respectively. In this study, the effect on $\Delta \mathrm{L}$ after a single brushing with BC was similar to whitening with HP-based whitening agents in the group stained with orange soda. However, after a second whitening session, HP showed better results than the 7 days of brushing with $\mathrm{BC}$. This result corroborates with previous studies ${ }^{26,27}$ and is mainly justified by the mechanical removal of extrinsic pigmentation, due to brushing abrasion. This may explain the fact that a single brushing with $\mathrm{BC}$ had a similar effect to HP in changing the luminosity of the group stained with OS. This dye has a lower pigment potential than GT and RW, which also justifies the pronounced effect of HP concerning $\mathrm{BC}$ to change $\Delta \mathrm{L}$ in subsequent assessments.

Studies on tooth whitening indicate that yellow-blue is the most important axis in the whitening perception. ${ }^{12,20}$ This axis is the one which promotes higher changes at the groups whitened with $\mathrm{BC}$, since it is already clear that the semi-transparent blue layer on the dental structure promoted by $\mathrm{BC}$ decreases the values of the $\mathrm{b}^{*}$ axis [yellow-blue], which reduces the teeth yellowed appearance and improving the whitening measurement and perception.$^{7}$ In the present study, $\mathrm{BC}$ promoted noticeable changes in the $\mathrm{b}^{*}$ axis. ${ }^{28}$ Not surprisingly, at $\mathrm{T} 1$ this effect was similar to HP for GT and control groups. These results were already expected and are in accordance with the comparison in non-pigmented teeth ${ }^{29}$, which highlighted that the promising effect of the blue film provided by $\mathrm{BC}$ to reduce teeth yellowing is less effective than conventional tooth whitening with severe pigmentation.

The greatest changes in $\Delta \mathrm{a}$ were observed in the groups stained with RW, where the effect of the type of whitening was not significant. The changes in these two groups were similar to HP in the group stained with GT. The greatest changes in groups with RW may be due to the main characteristic of the substance color, which alters the red-green axis. The hypothesis for the similarity of the effect of a single brushing with $\mathrm{BC}$ and a whitening session with $\mathrm{HP}$ is that RW pigmentation, although severe, is superficial. Taking this into account, it is possible to infer that the ability to remove extrinsically pigmented film by the abrasive brushing effect 
with whitening toothpaste is equivalent to the action of a single HP application. In GT pigmented tooth, pigment molecules are believed to have a superior ability to penetrate into the tooth structure, promoting a more significant change in pigmentation on the $\mathrm{a}^{*}$ axis and, thus, the HP effect is more significant.

The lack of studies that assessed the $\mathrm{WI}_{\mathrm{D}}$ of whitening toothpaste hinders a direct comparison of our findings. Higher $\mathrm{WI}_{\mathrm{D}}$ values represent greater whiteness. ${ }^{21}$ Thus, our findings suggest that hydrogen peroxide is more effective in promoting tooth whitening. An interesting finding of the whiteness potential was observed concerning the pigmented groups with RW, where the BC and HP effects were similar regardless of time. This finding can be justified by the higher pigmentation potential of RW than the other evaluated solutions. Thus, $\mathrm{BC}$ toothpaste associated with brushing abrasion may have accentuated the staining removal by RW, preventing a significantly higher effect of HP.

Toothpaste is an important vehicle for delivering therapeutic doses to the oral cavity during the daily brushing routine. Based on this, the incorporation of chemical, optical and/or abrasive properties have been added to promote whitening during the oral hygiene routine, trying to avoid the need for a conventional HP-based whitening procedure..$^{30}$ Regarding the effectiveness of whitening toothpastes with $\mathrm{BC}$ in their composition, it has been reported that 2 units are required to obtain a noticeable difference in teeth whitened by BC. ${ }^{28}$ In this study, alteration higher than 2 units was observed in all the groups that received BC. Thus, the results of this study suggest that the use of $\mathrm{BC}$ toothpaste has a whitening optical effect on the tooth structure, even in those with severe staining.

This in vitro study has some limitations. The absence of a control group with exposure to $\mathrm{BC}$ without brushing prevented confirmation that the removal of extrinsic stains can be attributed to an optical [blue layer] or mechanical [abrasion] effect. However, the synergic analysis of toothpaste + brushing is due to the attempt to reproduce the effect in the oral environment of this product, which will be conditioned to brushing. The use of bovine teeth can also be pointed out as a limitation, since its optical properties differ from those observed in human teeth. ${ }^{31}$ However, as this study employed a direct comparison with the baseline in the condition of the pigmented dental structures, it is believed that may reduce the possible bias of optical alteration of the dental structure on the measurement of color change.

The findings of this study agree with the current literature on the subject. Whitening toothpaste has a significant effect on removing extrinsic teeth staining, ${ }^{32}$ but has been associated with less color change compared to conventional whitening. ${ }^{33}$ Recent clinical evidence supports the scarce whitening potential of toothpaste containing blue covarine after a single application $^{34}$ or even after using it for 2 weeks. ${ }^{35}$

On the other hand, the use of BC toothpaste after in-office whitening has proven to be an effective strategy to maintain the whitening results. ${ }^{36}$ This can be attributed to the possible synergism between BC and HP. ${ }^{37}$ Therefore, after whitening teeth, the BC whitening effect is minimal but effective in the color maintenance. Future studies are needed to clarify if the insertion of whitening toothpaste in daily oral hygiene procedures of stained teeth patients can prevent the tooth pigmentation recurrence after at-home or in-office whitening and delay the need for new whitening procedures.

\section{Conclusion}

Within the limitations of this study, it can be concluded that BC may be a viable option for extrinsically stained teeth. However, for severe staining, BC exhibited minimal whitening effect and conventional HP-based whitening agents proved to be the most effective treatment strategy in this clinical situation. Perspectives for future studies on the subject should include the investigation of the potential of BC toothpaste in preventing the tooth pigmentation recurrence after at-home or in-office whitening and delay the need for new whitening procedures.

\section{References}

1. Rodríguez-Martínez J, Valiente M, Sánchez-Martín MJ. Tooth whitening: From the established treatments to novel approaches to prevent side effects. J Esthet Restor Dent 2019;31(5):431-40. doi: 10.1111/jerd.12519.

2. Alkahtani R, Stone S, German M, Waterhouse P. A review on dental whitening. J Dent 2020;100:103423. doi: 10.1016/j. jdent.2020.103423.

3. Joiner A. Review of the effects of peroxide on enamel and dentine properties. J Dent 2007;35(12):889-96. doi: 10.1016/j.jdent.2007.09.008.

4. Joiner A. The bleaching of teeth: a review of the literature. J Dent 2006;34(7):412-9. doi: 10.1016/j.jdent.2006.02.002.

5. Ribeiro APD, Sacono NT, Lessa FC, Nogueira I, Coldebella $\mathrm{CR}$, Hebling $\mathrm{J}$ et al. Cytotoxic effect of a $35 \%$ hydrogen peroxide bleaching gel on odontoblast-like MDPC-23 cells. Oral Surg Oral Med Oral Pathol Oral Radiol Endod 2009;108(3):458-64. doi: 10.1016/j.tripleo.2009.05.006.

6. Costa CA, Riehl H, Kina JF, Sacono NT, Hebling J. Human pulp responses to in-office tooth bleaching. Oral Surg Oral Med Oral Pathol Oral Radiol Endod 2010;109(4):e59-e64. doi: 10.1016/j.tripleo.2009.12.002.

7. Joiner A. Whitening toothpastes: a review of the literature. J Dent 2010;38 Suppl 2:e17-e24. 10.1016/j.jdent.2010.05.017

8. Bortolatto JF, Pretel H, Floros MC, Luizzi AC, Dantas AA, Fernandez E, et al. Low Concentration $\mathrm{H}(2) \mathrm{O}(2) / \mathrm{TiO} \_\mathrm{N}$ in Office Bleaching: a randomized clinical trial. J Dent Res 2014;93(7 Suppl):66S-71S. doi: 10.1177/0022034514537466.

9. Epple M, Meyer F, Enax J. A critical review of modern concepts for teeth whitening. Dent J (Basel) 2019;7(3):79. doi: $10.3390 / \mathrm{dj} 7030079$.

10. Joiner A, Philpotts CJ, Alonso C, Ashcroft AT, Sygrove NJ. A novel optical approach to achieving tooth whitening. J Dent 2008;36:S8-S14. doi: 10.1016/j.jdent.2008.02.005.

11. Kleber CJ, Putt MS, Nelson BJ. In vitro tooth whitening 
by a sodium bicarbonate/peroxide dentifrice. J Clin Dent 1998;9(1):16-21.

12. Goodson JM, Tavares M, Sweeney M, Stultz J, Newman M, Smith V, et al. Tooth whitening: tooth color changes following treatment by peroxide and light. J Clin Dent 2005;16(3):7882.

13. Luo W, Westland S, Brunton P, Ellwood R, Pretty IA, Mohan $\mathrm{N}$. Comparison of the ability of different colour indices to assess changes in tooth whiteness. J Dent 2007;35(2):109-16. doi: 10.1016/j.jdent.2006.06.006.

14. Luo W, Westland S, Ellwood R, Pretty I, Cheung V. Development of a whiteness index for dentistry. J Dent 2009;37(Suppl 1):e21-e26. doi: 10.1016/j.jdent.2009.05.011.

15. Joiner A, Philpotts CJ, Ashcroft AT, Laucello M, Salvaderi A. In vitro cleaning, abrasion and fluoride efficacy of a new silica based whitening toothpaste containing blue covarine. J Dent 2008;36(Suppl 1):S32-S37. doi: 10.1016/j.jdent.2008.02.003.

16. Baig A, He T, Buisson J, Sagel L, Suszcynsky-Meister E, White DJ. Extrinsic whitening effects of sodium hexametaphosphate: a review including a dentifrice with stabilized stannous fluoride. Compend Contin Educ Dent 2005;26(9 Suppl 1):47-53.

17. Sulieman MA. An overview of tooth-bleaching techniques: chemistry, safety and efficacy. Periodontol 2000 2008;48:14869. doi: 10.1111/j.1600-0757.2008.00258.x.

18. Faul F, Erdfelder E, Lang AG, Buchner A. G*Power 3: a flexible statistical power analysis program for the social, behavioral, and biomedical sciences. Behav Res Methods 2007;39(2):175-91. doi: 10.3758/bf03193146.

19. Stookey GK, Burkhard TA, Schemehorn BR. In Vitro Removal of Stain with Dentifrices. J Dent Res 1982;61(11):1236-9. doi: $10.1177 / 00220345820610110501$.

20. Cvikl B, Lussi A, Moritz A, Flury S. Enamel surface changes after exposure to bleaching gels containing carbamide peroxide or hydrogen peroxide. Oper Dent 2016;41(1):E3947. doi: 10.2341/15-010-L.

21. Pérez MM, Ghinea R, Rivas MJ, Yebra A, Ionescu AM, Paravina RD et al. Development of a customized whiteness index for dentistry based on CIELAB color space. Dent Mater 2016;32(3):461-7. doi: 10.1016/j.dental.2015.12.008.

22. Moncada G, Sepúlveda D, Elphick K, Contente M, Estay $\mathrm{J}$, Bahamondes $\mathrm{V}$ et al. Effects of light activation, agent concentration, and tooth thickness on dental sensitivity after bleaching. Oper Dent 2013;38(5):467-76. doi: 10.2341/12335-C.

23. Bergesch V, Baggio Aguiar FH, Turssi CP, Gomes França FM, Basting RT, Botelho Amaral FL. Shade changing effectiveness of plasdone and blue covarine-based whitening toothpaste on teeth stained with chlorhexidine and black tea. Eur J Dent 2017;11(4):432-7. doi: 10.4103/ejd.ejd_97_17.

24. Oliveira M, Fernández E, Bortolatto J, Oliveira Junior O, Bandeca M, Khajotia S et al. Optical Dental Whitening Efficacy of Blue Covarine Toothpaste in Teeth Stained by Different Colors. J Esthet Restor Dent 2016;28(Suppl 1):S68-
77. doi: 10.1111/jerd.12204.

25. CIE publication No. 15.2. CIE Colorimetry. Paris: Central Bureau of the CIE; 1986.

26. Collins LZ, Naeeni M, Platten SM. Instant tooth whitening from a silica toothpaste containing blue covarine. J Dent 2008;36:S21-S25. doi: 10.1016/j.jdent.2008.02.006.

27. Alshara S, Lippert F, Eckert GJ, Hara AT. Effectiveness and mode of action of whitening dentifrices on enamel extrinsic stains. Clin Oral Investig 2014;18(2):563-9. doi: 10.1007/ s00784-013-0981-8.

28. Westland S, Luo W, Li Y, Pan Q, Joiner A. Investigation of the perceptual thresholds of tooth whiteness. J Dent 2017;67S:S11-S14. doi: 10.1016/j.jdent.2017.09.013.

29. Dantas AA, Bortolatto JF, Roncolato Á, Merchan H, Floros MC, Kuga MC et al. Can a bleaching toothpaste containing Blue Covarine demonstrate the same bleaching as conventional techniques? An in vitro, randomized and blinded study. J Appl Oral Sci 2015;23(6):609-13. doi: 10.1590/1678775720150268.

30. Joiner A. Review of the extrinsic stain removal and enamel/ dentine abrasion by a calcium carbonate and perlite containing whitening toothpaste. Int Dent J 2006;56(4):175-80. doi: 10.1111/j.1875-595x.2006.tb00091.x.

31. Yassen GH, Platt JA, Hara AT. Bovine teeth as substitute for human teeth in dental research: a review of literature. J Oral Sci 2011;53(3):273-82. doi: 10.2334/josnusd.53.273.

32. Soeteman GD, Valkenburg C, Van der Weijden GA, Van Loveren C, Bakker E, Slot DE. Whitening dentifrice and tooth surface discoloration-a systematic review and meta-analysis. Int J Dent Hyg 2018;16(1):24-35. doi: 10.1111/idh.12289.

33. Jiang N, Zhang C, Agingu C, Attin T, Cheng H, Yu H. Comparison of whitening dentifrices on the effectiveness of in-office tooth bleaching: a double-blind randomized controlled clinical trial. Oper Dent 2019;44(2):138-45. doi: 10.2341/17-333-C.

34. Schlafer S, Poulsen PN, Johansen J, Trap L, Leite FRM. The whitening effect of single brushing with blue-covarine containing toothpaste: a randomized controlled trial. J Dent 2021;105:103559. doi: 10.1016/j.jdent.2020.103559.

35. Meireles SS, de Sousa JP, Lins RBE, Sampaio FC. Efficacy of whitening toothpaste containing blue covarine: a doubleblind controlled randomized clinical trial. J Esthet Restor Dent 2021;33(2):341-350. doi: 10.1111/jerd.12605.

36. Jiang N, Zhang C, Agingu C, Attin T, Cheng H, Yu H. Comparison of whitening dentifrices on the effectiveness of in-office tooth bleaching: a double-blind randomized controlled clinical trial. Oper Dent 2019;44(2):138-145. doi: 10.2341/17-333-C.

37. Bortolatto JF, Dantas AA, Roncolato Á, Merchan H, Floros $\mathrm{MC}$, Kuga $\mathrm{MC}$, et al. Does a toothpaste containing blue covarine have any effect on bleached teeth? An in vitro, randomized and blinded study. Braz Oral Res 2016;30:S180683242016000100226. doi: 10.1590/1807-3107BOR-2016. vol30.0033. 